\title{
PERFORMATIVIDADES GOVERNAMENTAIS DE FRONTEIRA: A PRODUÇÃO DO ESTADO E DA FRONTEIRA POR MEIO DE POLÍTICAS DE TRÁFICO DE PESSOAS NA AMAZÔNIA BRASILEIRA ${ }^{1}$
}

\author{
José Miguel Nieto Olivar²
}

\begin{abstract}
RESUMO
O objetivo desse artigo é mostrar como o Estado se produz nestas fronteiras internacionais a partir da operação capilar de políticas/discursos públicos e como nesse processo se produz "a fronteira" enquanto imagem e "as margens" enquanto relações. Como chave etnográfica de acesso para observar essas formas empíricas e performativas de gestão do Estado, usarei as maneiras como as políticas/discursos de tráfico de pessoas, em relação com exploração sexual e com políticas de fronteiras, têm sido produzidas em duas cidades de fronteiras internacionais amazônicas: Tabatinga e São Gabriel da Cachoeira. A ideia de governamentalidade e de performatividade associada a esta me permitirá fazer ênfase na produção ativa, enunciativa, às vezes espetacular, e criativa de formas locais de poder nas quais se conectam instituições estatais, lideranças sociais, instituições religiosas, mídia, entre outras. Esse artigo é resultado de um processo de pesquisa ao redor dos mercados do sexo e suas políticas, especialmente as políticas antitráfico em fronteiras amazônicas.
\end{abstract}

Palavras-chave: Exploração Sexual. Gênero. Sexualidade. Políticas. Amazonas. Fronteiras.

\footnotetext{
${ }^{1}$ Esse artigo é resultado dos múltiplos e enriquecedores intercâmbios ao interior do Núcleo Pagu, especialmente através dos grupos de estudo promovidos pela Dra. Piscitelli com suas orientandas e supervisadas, espaço no qual aconteceram valiosos debates ao redor do estudo das articulações entre gênero, afetos, sexualidades, economias e Estado; bem como sobre "fronteira" e, claro, sobre tráfico. Algumas ideias ou rascunhos que depois foram incorporados nesse texto foram lidos e discutidos nestes espaços. Agradeço então a Adriana, a Iara Beleli, Aline Tavares, Paula Togni, Natalia Padovani, Bruna Bumachar, Laura Lowenkron, Carolina Branco, Paula Luna, Anna Paula Araujo e Carol Pavajeau. Também agradeço a Lindomar Albuquerque pelas reflexões e dicas no estudo das fronteiras, pela leitura cuidadosa e pelo impulso que sempre deu. Finalmente, agradeço a Dario Muñoz pelas conversas sobre "governamentalidade".

${ }^{2}$ Núcleo de Estudos de Gênero PAGU/Unicamp. Auxílio FAPESP Jovem Pesquisador, processo 2013/26826-2. E-mail: escreve.ze@ gmail.com
} 


\begin{abstract}
This article aims to show how the state is produced in these Brazilian amazon international borders from the capillary operation of policies and public discourses and how in this process "the border" as a concept and "the margins" as relations are produced, too. As ethnographic key to access the empirical and performative ways of state's management I will use the ways in which the policies/discourses of human trafficking, connected with those of sexual exploitation and of borders, have been produced in two Amazonian cities in international borders: Tabatinga and Sao Gabriel da Cachoeira. The ideas of governmentality and of performative acts will allow me to emphasize the active, creative, enunciative and sometimes spectacular production of local forms of power that connects state institutions, social leaderships, religious institutions, mass media, among others. This article is resultant of a research process about the sex markets and its policies/politics, specially the antitraffic policies, in Brazilian amazon borders.
\end{abstract}

Keywords: Sexual Exploitation. Gender. Sexuality. Policies. Amazon. Borders. 


\section{Introdução}

O objetivo desse artigo é mostrar como o Estado, como um processo multidimensional e descentrado (SHARMA e GUPTA, 2006), se produz nestas fronteiras internacionais a partir da operação capilar de políticas/discursos públicos e como nesse processo se produz "a fronteira" enquanto imagem e "as margens" enquanto relações (DAS e POOLE, 2008) entre Estado e população local, entre os diferentes níveis e âmbitos do próprio Estado, e, inclusive, enquanto forma de se perguntar sobre os limites do que chamamos de Estado. Como chave etnográfica de acesso para observar essas formas empíricas e performativas de gestão do Estado, usarei as maneiras como as políticas/discursos de tráfico de pessoas, em relação com exploração sexual e com políticas de fronteiras, têm sido produzidas em fronteiras internacionais amazônicas.

Nesse sentido, recorro à noção de governamentalidade, derivada das análises foucaultianas sobre biopolíticas e distribuição e capilaridade do poder, para nominar arquiteturas de poder, de controle e de regulação que fluem entre os diversos níveis do Estado, são "exercidas" e recriadas em práticas locais, e desdobram e ultrapassam institucionalidades mais clássicas e explícitas associadas ao Estado, isto é: agências de cooperação, organismos multilaterais, instituições religiosas, organizações locais de poder, entre outras (FOUCAULT, 2008; LEMKE, 2000). Demonstro como essa produção de Estado e de governamentalidade está fortemente marcada por gênero, condição econômica, procedência e etnia, e por assimetrias de poder dentro do Estado e no marco das relações sociais locais. A noção de "atos performativos" desenvolvida por Butler (1990) para compreender as formas corporificadas, criativas, fluídas, práticas e relacionais em que o gênero (as relações de, as identidades de) é produzido, pode me auxiliar no intuito de entender como o Estado e a fronteira vistos etnograficamente emergem também de um conjunto de atos de enunciação que não são meras expressões de estruturas gramáticas anteriores (legislações e políticas centralizadas), e que são produtores de gênero.

A razão de escolher as políticas antitráfico na fronteira como chave etnográfica de entrada obedece ao meu percurso particular de pesquisa que tem como nicho institucional o Núcleo de Estudos de Gênero 
PAGU. Entre 2010 e 2013 realizei uma pesquisa de pós-doutorado sob supervisão da Dra. Adriana Piscitelli sobre mercados do sexo na tríplice fronteira entre o Brasil, a Colômbia e o Peru, pontualmente, na cidade transfronteiriça composta por Tabatinga (Br), Leticia (Col) e Santa Rosa (Pe). Como parte desse projeto, em 2010 acompanhei um levantamento rápido de informações para um projeto da Secretaria de Direitos Humanos da Presidência da República sobre o sistema de garantia de direitos para o enfrentamento ao "tráfico de crianças e adolescentes com fins de exploração sexual" em tríplices fronteiras amazônicas. Posteriormente, realizei trabalho de campo etnográfico com base em Tabatinga durante aproximadamente quatro meses em 2011 e quatro meses em 2012, focado na compreensão dos "mercados do sexo" e das suas políticas com relação aos "processos de fronteirização" e de produção da Amazônia. A partir do segundo semestre de 2013 participei de uma pesquisa coordenada pela Dra. Piscitelli chamada "Trânsitos, crime e fronteiras: gênero, tráfico de pessoas e mercados do sexo no Brasil", levantando informações mais pontuais em Tabatinga, São Gabriel da Cachoeira (AM) e Altamira (PA) referentes à capilarização dos discursos/políticas de enfrentamento ao tráfico de pessoas.

Atualmente estou desenvolvendo um novo processo de pesquisa, derivado dessas anteriores e do processo de aprendizado no Núcleo, que busca compreender as formas como gênero se articula nos processos de fronteirização amazônica contemporânea, levando em particular consideração os processos de Estado e as dinâmicas sexuais e econômicas. Esse artigo, então, é parte do exercício de olhar transversalmente para esse processo de pesquisa, escolhendo alguns pequenos recortes e informações pontuais e fazendo ênfase na dimensão das políticas públicas de produção de fronteiras amazônicas; esse artigo incorpora partes e referências do meu relatório de pósdoutorado (OLIVAR, 2013) e da minha sessão no relatório da pesquisa CNPq coordenada pela Dra. Piscitelli (PISCITELLI et ali, 2015) ${ }^{3}$.

Menos que refletir sobre prostituição, mercados do sexo, tráfico de pessoas ou exploração sexual, meu objetivo nesse artigo é atentar aos "processos de fronteirização" (GRIMSON, 2003; ALBUQUERQUE,

${ }^{3}$ Pesquisa de pós-doutorado apoiada pela FAPESP (processo 2010/50077-1), pesquisa "Trânsitos, crimes e fronteiras..." apoiada pelo CNPq (processo 404868/2012-6) e pesquisa vigente com auxílio "Jovem Pesquisador" da FAPESP (processo 2013/26826-3). 
2015) desde a perspectiva particular da governamentalidade, por tanto, à gestão multidimensional, carnal, processual do Estado, tendo como centro a fronteira (ZÁRATE, 2008). Nesse sentido, tenho abordado $a$ fronteira como uma ordem territorial concreta importante para a produção do Estado e de outras formas de poder $\mathrm{e}$ governamentalidade: essas "fronteiras internacionais" jurídica, política, midiática e massivamente compreendidas como tais.

Porém, esse movimento implica compreender a construção presente, polifônica e processual (performativa) desse acordo massivo que nos permite dizer com facilidade que Tabatinga "é" fronteira; isto é, seguindo as análises de Margarita Serje (2005) sobre o processo histórico de construção das fronteiras na Colômbia, vale a pena atentar não somente aos territórios de fronteira, mas se perguntar como o "mito-conceito" que seria a fronteira é recriado e operacionalizado em ordens práticas do cotidiano marcando determinados territórios e populações. Seguir esse movimento, sem perder de vista a ênfase territorial e de ponto de vista implicada na etnografia e nas propostas de Grimson (2003), Zárate (2008) e Albuquerque (2010), implica aproximar-se à "fronteira" não como uma categoria capaz de explicar as formas do Estado local ou determinadas dinâmicas sociais (tipicamente no limite entre legal e ilegal), mas desde a sua construção êmica, política e simbólica, territorializada, ao mesmo tempo discursiva, imagética e intensamente material, mobilizada pelos mais diversos agentes em tensão. Meu interesse de pesquisa, do qual esse artigo é um pequeno exercício, é compreender quais as formas, limites e conteúdos dessa ideia atomizada e altamente disponível, quais as suas tensões, quais os agentes que a mobilizam, e qual é o lugar do gênero nesse processo.

É nesse sentido que a recente articulação entre os discursos e as políticas brasileiras de combate ao tráfico de pessoas e as políticas de segurança, defesa e integração das fronteiras parece ser um espaço útil para compreender empiricamente como essas "fronteiras" são pensadas, imaginadas e produzidas, e como o Estado e outras formas de governamentalidade se produzem a partir dessa articulação.

Na primeira parte do artigo apresento um panorama da articulação entre políticas antitráfico e políticas de fronteiras no Brasil contemporâneo no plano da produção de objetos políticos de nível federal ou regional. Meu intuito é mostrar como está sendo tecida essa 
articulação, a partir de que noções de fronteira, de Amazônia e de tráfico e com a participação privilegiada de quais agentes. Na segunda parte do artigo apresento duas narrativas provenientes do trabalho de campo em duas cidades amazônicas fronteiriças que permitem ver em um corte temporal, de 2010 a 2014, as maneiras como os discursos do tráfico são capilarizados e produzidos localmente e como nessa capilarização o Estado e a fronteira encontram um lugar fértil de performatividade, emergência e recriação. Finalmente, ofereço algumas reflexões sobre os efeitos da articulação entre políticas antitráfico de pessoas/exploração sexual, e políticas de fronteiras, tanto para a construção das ações capilares da luta contra o tráfico, quanto para o "processo de fronteirização" vigente.

\section{Fronteiras, Amazônia e o enfrentamento ao tráfico-de- pessoas/exploração-sexual}

As políticas e os discursos de combate ao tráfico de pessoas no Brasil vêm ganhando força desde a publicação, em 2002, da Pesquisa sobre Tráfico de Mulheres, Crianças e Adolescentes no Brasil -PESTRAF (LEAL e LEAL, 2002). Desde 2002 até hoje o principal foco das atenções nessa política tem sido os deslocamentos transnacionais de mulheres brasileiras para o norte global em função da sua participação nos "mercados do sexo"; por outro lado, em associação com "turismo sexual", as viagens de homens europeus para o Brasil (especialmente para o litoral sudeste e nordeste) têm sido alvo de campanhas e preocupações governamentais (PISCITELLI 2005; 2013). Portanto, talvez os dois principais "territórios" focados nesses anos no antitráfico brasileiro tem sido os aeroportos internacionais e os circuitos turísticos praianos (principalmente do nordeste). Por outro lado, como veremos, tem existido uma preocupação constante com "as rotas" de tráfico interno e internacional de pessoas por todo o Brasil e com a saída de brasileiras pelas fronteiras internacionais, especialmente no norte e nordeste amazônico. Esses discursos e políticas têm priorizado nas suas conceitualizações e na sua ação o tráfico de pessoas que teria por finalidade a "exploração sexual", entendida ora como prostituição, ora como "prostituição de menores" e em outras vezes como exploração comercial da prostituição de outrem; isso implicou, desde o início, uma confusão e apagamento de limites entre as diferentes categorias jurídicas que são "tráfico" e 
“exploração". Nesse panorama específico, até 2010 "fronteiras" serviu principalmente como referência para descrever processos de mobilidade transnacional, a maior parte das vezes transhemisférica e transoceânica ${ }^{4}$.

Se bem a presença de uma preocupação específica com a "região norte" e as fronteiras não são novas na trajetória das políticas/discursos de tráfico no Brasil, nos últimos cinco anos ganhou força e especificidade através de alguns objetos políticos específicos que nos servem de marcadores. Esses objetos são constructos sócio-políticos, atos performativos documentais ora do Estado ora de outros agentes de governamentalidade no seu processo multidimensional de gestão.

Fronteiras e "região norte" já estavam colocadas na Pesquisa sobre Tráfico de Mulheres, Crianças e Adolescentes no Brasil (PESTRAF) (LEAL e LEAL, 2002), realizada pela Organização Não Governamental (ONG) Centro de Referência, Estudos e Ações sobre Crianças e Adolescentes (CECRIA) com o apoio de grandes ONGs internacionais, da agência de cooperação do governo dos Estados Unidos e do governo federal brasileiro. Nela aparecem mais de 76 "rotas de tráfico" nacionais, internacionais e transcontinentais na região norte (das 241 que afirmam existir no país) e são mencionadas (sem qualquer descrição ou análise) caraterísticas "geográficas e culturais da Amazônia (Acre, Rondônia, Pará, Roraima, Amazonas, Amapá e Tocantins), sua história e os planos para o seu desenvolvimento" (LEAL e LEAL, 2002: 77-78) como determinantes que "favorecem" o tráfico. Entre estas estão as fronteiras sem fiscalização, a migração desordenada e a (supostamente) frágil presença das instituições governamentais.

Na Região Amazônica, migrar em busca de oportunidades de empregos temporários e de renda rápida, constitui-se para muitas pessoas, especialmente para mulheres pobres,

\footnotetext{
${ }^{4}$ As políticas brasileiras de enfrentamento ao tráfico de pessoas podem ser consultadas no site do Ministério da Justiça, enquanto crime penal está definido nos artigos 131 e 131A do Código Penal. Por outro lado, é importante sublinhar que os princípios e metodologias destas políticas, bem como as maneiras não sempre claras nem confiáveis como o conhecimento sobre tráfico de pessoas tem se produzido no Brasil, e os efeitos contraditórios e prejudiciais que têm mostrado no sentido de reprimir a prostituição e a migração, entre outras, são objeto de uma consistente crítica baseada fundamentalmente em pesquisa etnográfica; ver, por exemplo, Grupo DAVIDA (2005), Piscitelli (2011, 2008b), Teixeira (2008), Blanchette \& Silva (2012), Lowenkron (2014) Sprandel (2014), Piscitelli et ali (2015).
} 
via mercado do sexo, uma das poucas opções para fugir da pobreza.

Com os altos lucros, a frágil presença do Estado e a corrupção, o crime organizado avançou na região, através do contrabando de ouro, armas, drogas e outros. Deste modo, construiu-se um cenário no qual o tráfico foi sendo incorporado ao discurso e na cultura local, como inevitável. (LEAL e LEAL, 2002: 80).

No Relatório Final desta pesquisa as autoras fazem algumas recomendações entre as quais aparece a necessidade de prestar maior atenção ao "tráfico nas fronteiras" por uma série heterogênea de razões que incluem circulação das pessoas sem controles, duplicidade de moedas, instabilidade econômica e "um comercio sexual ligado à dinâmica produtiva local” (LEAL e LEAL, 2002: 215-216). Nesse sentido, como era esperável, se recomenda promover a fiscalização nas fronteiras incluindo melhores condições salariais para os agentes de defesa e segurança.

A partir da sua participação na PESTRAF na "região norte", a ONG Sodireitos, junto com as organizações não governamentais internacionais Global Alliance Against Trafficking in Women (GAATW) e seu capítulo latino-americano, a REDLAC, realiza a Pesquisa Tri-nacional sobre Tráfico de Mulheres do Brasil e da República Dominicana para o Suriname (SODIREITOSGAATW/REDLAC, 2008). A preocupação fundamental era com "tráfico de mulheres" para exploração sexual, particularmente do estado do Pará, associado à migração, a prostituição e à lógica das "rotas". O enfoque é próximo da PESTRAF, contudo, essa pesquisa procura ter maior cuidado no uso de categorias e referências, e afirma estar baseada em dados e pessoas "reais". Apesar de estar em uma região de fronteira e de lidar com mobilidades e relações transfronteiriças, nessa pesquisa a fronteira manteve sua condição de porta de entrada e de saída, abordagem já presente desde algumas das primeiras pesquisas e intervenções promovidas pelo Ministério da Justiça em cidades de origem e nas quais estavam sediados os principais aeroportos internacionais (Goiânia, Fortaleza, São Paulo e Rio de Janeiro) (PISCITELLI, 2013). Amazônia ocupa em geral um lugar de pano de fundo, contudo, uma leitura particular da história, das dinâmicas sociais e econômicas, das "lógicas migratórias" e das relações de gênero-e-sexualidade de uma Amazônia que parece homogênea são usadas como parte das "bases estruturais, objetivas e 
subjetivas" (SODIREITOS-GAATW/REDLAC, 2008, p.34) para explicar o tráfico. Vale a pena destacar que, como preocupações particulares dos pesquisadores responsáveis, as recomendações dessa pesquisa não incluem qualquer menção à necessidade de fortalecer a vigilância e os controles migratórios e fronteiriços, pelo contrário, faz um esforço em desestimular tal lógica, focando mais as sugestões na intervenção sobre desigualdades econômicas e de gênero. Isso revela uma importante margem de agência e diferenciações políticas na produção de conhecimento.

Contudo, o primeiro projeto que associou com alto valor heurístico Amazônia, território de fronteira, tráfico de pessoas e exploração sexual de menores de 18 anos foi o Projeto Fronteiras, desenvolvido em 2010 pela Secretaria de Direitos Humanos da Presidência da República junto com a ONG paulista ASBRAD, que consistiu num levantamento de informações em quatro cidades de tríplice fronteira internacional na Amazônia ("arco norte") sobre o sistema de garantia de direitos no referente a "tráfico de crianças e adolescentes com fins de exploração sexual" (ASBRAD, 2012). Esse projeto não foi resultado de uma gestão da Secretaria Nacional de Justiça, responsável pela política antitráfico, mas da Secretaria dos Direitos Humanos, responsável, entre outras coisas, pelas políticas de proteção de direitos humanos de crianças e adolescentes e dos programas federais de enfrentamento à exploração sexual dessa população. No início da minha pesquisa de pós-doutorado, tive a oportunidade de acompanhar esse levantamento. As ações do projeto em campo implicaram, de fato, uma cobrança federal às instituições nos locais sobre as temáticas, e mobilizaram algumas ações, digamos, demonstrativas. O relatório do Projeto Fronteiras, que levantava graves problemas e inconsistências nas políticas e na operação do Estado nesses locais - incluídas as forças de segurança e defesa - e pouquíssimas evidências de tráfico de pessoas, circulou pela Secretaria Nacional de Justiça e nunca foi publicado. O relatório incluía também a preocupação da equipe com os discursos acusatórios sobre "as culturas locais" e sobre a necessidade de fechamento ou de maior fiscalização nas fronteiras que foram recorrentes durante o levantamento.

Outro relevante objeto político nessa construção provém da própria região amazônica, da parceria entre o âmbito acadêmico e o judiciário. Em 2012, duas pesquisadoras e professoras universitárias da Universidade Federal de Amazonas publicaram um livro chamado 
Tráfico de Mulheres na Amazônia (TORRES e OLIVEIRA, 2012), baseado em duas fontes principais: a pesquisa de mestrado de uma das autoras sobre tráfico de mulheres "amazônidas" na Espanha (OLIVERIA, 2011) e um estudo realizado em conjunto com o Ministério Público Federal no estado do Amazonas que, segundo consta na publicação, consistiu na aplicação de uma enquete de dez perguntas fechadas a 171 pessoas que participavam de uma audiência pública sobre tráfico de pessoas em Manaus. O livro tenta afirmar uma vulnerabilidade especial e particular da Amazônia (e das mulheres "amazônidas") para o tráfico de mulheres baseado em "determinantes sociais" entre os quais se destaca a "origem étnica" da população do Amazonas em relação com as assimetrias coloniais e de gênero, e com os desejos das "hostes conquistadoras" (TORRES e OLIVEIRA, 2012: 95-97).

Nesse sentido, esse texto apresenta uma perspectiva próxima ao que Schiller e Salazar (2012) denominam "nacionalismo metodológico" na sua abordagem da questão migratória, central na compreensão sobre Amazônia, mobilidades, gênero e fronteiras, que leva as autoras a sugerir as mobilidades e a facilidade no atravessamento de fronteiras como um "determinante" do tráfico 5 .

Outro determinante histórico-social somado ao fenômeno transnacional de tráfico de mulheres é o crescente processo migratório intraregional e fronteiriço que, a um passo, está-se em outro país. As pessoas são atraídas para trabalhar fora de seu país, também, pela facilidade que as fronteiras aparentemente apresentam (TORRES e OLIVEIRA, 2012, p. 24).

Esse livro tem sido bastante divulgado e usado em recentes atividades de sensibilização ao antitráfico no Amazonas.

Um quinto marcador importante é o Diagnóstico sobre Tráfico de Pessoas em áreas de Fronteira (BRASIL, 2013a), realizado em 2012 pela Secretaria Nacional de Justiça (SNJ), junto à organização europeia International Centre for Migration Policy Development (ICMPD) e ao Escritório das Nações Unidas para as Drogas e o Crime (UNODC), e

${ }^{5}$ Segundo esses autores, o "nacionalismo metodológico" é "[...] uma orientação ideológica que aborda o estudo de processos sociais e históricos como se estes fossem contidos dentro de fronteiras de estados-nações individuais" e constitui um dos principais problemas detectados nos estudos de migração. Ver também Togni nesse dossiê. 
que é resultado do cruzamento entre políticas de enfrentamento ao tráfico de pessoas e políticas de fronteiras no âmbito das gestões multilaterais e federais de governamentalidade disciplinar e biopolítica. Esse objeto político é resultado direto dos novos giros do discurso antitráfico no Brasil e do seu encontro com as políticas federais de fronteiras.

Nos últimos anos presenciamos um revigoramento da preocupação com as fronteiras internacionais nos governos estaduais e federal ao redor dos conceitos chave de "segurança", "desenvolvimento" e "integração", além da "defesa" (HIRATA, no prelo). Uma larga retórica de criminalidade, ilegalidade e ameaças, articuladas com ideias sobre pobreza, subdesenvolvimento ou "atraso" de algumas regiões fronteiriças orienta as formas atuais dessas políticas. O principal documento marco desses novos rumos e investimentos federais é de 2010: "Bases para uma política de Integração e Desenvolvimento da Faixa de Fronteira”, que tem como objetivo o "aperfeiçoamento da gestão das políticas de integração fronteiriça" e, "de maneira subsidiária", a integração fronteiriça com os países vizinhos "sulamericanos", especialmente vinculados ao Mercosul (Brasil, 2010). O Plano se define como a "principal ação de enfretamento à criminalidade na divisa do Brasil com países vizinhos" e no seu marco tem se desenvolvido grandes e espetaculares operações de forças de defesa e de segurança pública combinadas, como a Sentinela, a Ágata (com sete versões) e a Fronteira Segura. Nenhum desses documentos, desses operativos e das narrativas de agentes do Estado a quem tive acesso (militares do exército e policiais federais) nesse contexto priorizavam ou faziam qualquer menção específica, até 2013, ao tráfico de pessoas.

Porém, o Ministério da Justiça, em resposta ao Plano Estratégico de Fronteiras (2011), elabora entre 2011 e o início de 2012 a Estratégia Nacional de Segurança Pública nas Fronteiras (ENAFRON), coordenada pela Secretaria Nacional de Segurança Pública (SENASP), focada no controle policial e militar das fronteiras e na repressão à criminalidade. Como parte dessa estratégia, a Secretaria Nacional de Justiça, responsável federal pelo combate ao tráfico de pessoas, adquire responsabilidades específicas: a) elaborar um diagnóstico sobre tráfico de pessoas em áreas de fronteira -ao qual me referi anteriormente-, b) implementar Postos Avançados de Atenção Humanizada ao Migrante, e c) promover ações de cooperação jurídica 
internacional ${ }^{6}$. Finalmente, o II Plano de Enfrentamento ao Tráfico de Pessoas, publicado em 2013 e produzido a partir de 2011 com participação de atores dos direitos humanos e dos direitos de crianças e adolescentes, reflete esse conjunto de preocupações (BRASIL, 2013b).

Desse modo, durante 2012 a Secretaria Nacional de Justiça (SNJ), junto ao ICMPD e ao UNODC, prepararam o Diagnóstico que foi realizado e publicado em 2013 aplicando uma metodologia usada pelo ICMPD em fronteiras europeias. É relevante para esse artigo anotar que a metodologia estava baseada, de um lado, na pesquisa em cidades capitais dos estados com fronteiras internacionais (como Manaus), e não nas cidades fronteiriças ou nas faixas de fronteira (como Tabatinga ou Benjamin Constant, entre outras, para o nosso caso), e do outro, em fontes secundárias tratadas como fontes primárias: jornalistas, pesquisadores, ONGs, agentes do Estado, entre outros. Isto é, a metodologia privilegiou uma lógica epistemológica de centralismo e de distanciamento das pessoas, das relações e dos territórios específicos que pretendeu "diagnosticar". Membros de organizações entrevistadas e pesquisadores que participaram na elaboração desse diagnóstico levantaram duras críticas às maneiras "antiéticas" como a informação foi manejada em prol de reafirmar o supervalorado discurso do tráfico e de "vulnerabilidade" das regiões e populações fronteiriças. $\mathrm{O}$ documento dessa pesquisa foi rapidamente divulgado e tem sido massivamente usado, também, em processos educativos e é referência obrigatória para os dispositivos do Estado responsáveis capilarmente pela política (Núcleos de Enfrentamento ao Tráfico de Pessoas e Postos de Atendimento Humanizado ao Migrante) ${ }^{7}$.

Assim, por essa trilha, chegamos finalmente a 2014 e à capilaridade efetiva do antitráfico através da Campanha da Fraternidade 2014 da Igreja Católica: Fraternidade e Tráfico Humano, promovida e

${ }^{6}$ Fonte: Termos de Referência para a Pesquisa Nacional sobre Tráfico de Pessoas nas Áreas de Fronteiras: ICMPD/UNODC/SNJ, 2012. Ver também: Vacancy Announcement 12P116V01 -Research Coordination in Brazil: Assessment of Trafficking in Persons in the Border Areas; ICMPD.

${ }^{7}$ Como já é tradição na produção de conhecimento sobre tráfico de pessoas no Brasil e no mundo (Grupo DAVIDA, 2005; KEMPADOO, 2005, 2007AGUSTIN, 2007; PISCITELLI, 2008; O’CONNELL DAVIDSON, 2012), esses documentos que associam tráfico e fronteiras apresentam diversas e inconsistentes definições de "tráfico" e uma carência significativa de evidencias empíricas e de dados que justifiquem as intervenções que demandam (como disse anteriormente, o estudo de Sodireitos se coloca numa posição diferente do resto, pelo cuidado dos dados e a prevenção com os discursos de segurança e defesa). 
gerenciada pela Comissão Nacional dos Bispos do Brasil. A Campanha da Fraternidade produz de maneira centralizada as guias para a reprodução local dos materiais pedagógicos, publicitários e de sensibilização, e a noção de "tráfico humano" que vem mobilizando está baseada numa releitura católica dos acordos internacionais políticos presentes no Protocolo de Palermo ${ }^{8}$. Segundo material de divulgação em Tabatinga o objetivo da Campanha era:

Sensibilizar as pessoas no tocante à violação da dignidade humana das vítimas do tráfico, que na vida e no trabalho são barbaramente exploradas, seja no mercado do sexo, seja em atividades produtivas agrícolas ou industriais. Com frequência, o tráfico de pessoas está ligado ao fenômeno das migrações e à permanência ilegal e precária no país (Diocese do Alto Solimões, 2013 [grifo meu]). Segundo o mesmo documento, “a Amazônia é vulnerável à exploração de mulheres, crianças e adolescentes" e "Em Tabatinga, Leticia e cidades fronteiriças, a realidade se agrava ainda mais". Como efeito da Campanha aparecem com força agentes institucionais católicos na região amazônica como a Rede Grito pela Vida, organização de religiosas dedicada ao combate ao tráfico e que, segundo uma colega pesquisadora que vem acompanhando algumas atividades dessa rede, tem realizado grandes eventos de "capacitação" e "sensibilização" mobilizando importantes quantidades de dinheiro 9 .

Vemos então o caminho pelo qual as políticas/discursos de combate ao tráfico de pessoas/exploração sexual têm alcançado uma capilaridade insuspeitada anos atrás. Nesse desenho, como já tem sido descrito largamente para o caso brasileiro (ver as referências nesse artigo), ressalta a gestão laboriosa de uma rede de governamentalidade afincada no governo federal que tem criado o problema do "tráfico de pessoas" no Brasil e tem expandido e multiplicado suas abordagens, suas formas e suas necessidades de gestão política, que inclui agências internacionais, organismos multilaterais, universidades públicas, diversos âmbitos do governo, mídia, grupos e instituições religiosas, entre outras. Nesse processo, a dimensão da criminalidade implicada nas políticas antitráfico, e portanto da segurança pública, tem ampliado sua hegemonia sobre a dimensão dos direitos humanos; esse processo parece ganhar força quando se prefiguram territórios de fronteira,

\footnotetext{
${ }^{8}$ Sobre as conceptualizações de tráfico ver Piscitelli (2013).

${ }^{9}$ Ver http://gritopelavida.blogspot.com/ Agradeço a Susanne Hoffman pelas informações.
} 
mobilizando argumentos para o incremento da vigilância, do controle policial ou militar e para a repressão.

Então, como é que as políticas antitráfico estão produzindo essas fronteiras? Como é essa capilaridade que parte de supostos generalizantes da fronteira e da Amazônia? Que reverberação estão tendo essas políticas e discursos? Que significa afirmar a "efetiva capilaridade" através do trabalho da Igreja Católica? Como isso acontece? Que relações existem entre as disposições estatais, suas articulações multilaterais e as operações locais da Igreja Católica? Para aproximar-nos a respostas possíveis para estas perguntas, resulta importante apresentar alguns dados provenientes do meu trabalho de campo etnográfico.

\section{No campo: produção capilar do Estado, do tráfico/exploração e da fronteira}

O objetivo dessa sessão do artigo é mostrar como tem acontecido, na minha experiência de pesquisa, a capilarização do encontro entre políticas de fronteiras, políticas antitráfico de pessoas e políticas de enfrentamento à exploração sexual. Uso duas narrativas provenientes de duas cidades amazônicas fronteiriças: São Gabriel da Cachoeira e Tabatinga, ambas no estado de Amazonas ${ }^{10}$. Essas narrativas apresentam dinâmicas e eventos sociais e políticos ainda em desenvolvimento, cujos desdobramentos mais recentes estão em processo de pesquisa. Como já afirmei, o que me interessa é mostrar o Estado e a fronteira em pleno processo de gestação e gestão mútua.

\footnotetext{
${ }^{10}$ São Gabriel da Cachoeira e Tabatinga estão em regiões de fronteiras internacionais amazônicas com a Colômbia, o Peru e a Venezuela, bastante diferentes entre si, mas ambas com longos processos de colonização militar, importante preservação da floresta, e massiva presença indígena. A primeira é uma cidade tida como indígena, no Alto Rio Negro, com uma população urbana próxima dos 20.000 habitantes, distante das linhas fronteiriças e fortemente marcada pela vasta e densa floresta, pelas presenças indígenas, militares e religiosas (LASMAR, 2005; ANDRELLO, 2006). A segunda é uma intensa cidade transfronteiriça conurbada com Leticia (Col) e com a ilha de Santa Rosa (Pe), de mais de 60.000 habitantes, e conectada com uma diversidade de cidades, comunidades e aldeias de diversas escalas desses três países (APONTE-MOTA, 2011; OLIVAR, 2013; ALBUQUERQUE e PAIVA nesse dossiê).
} 


\section{Narrativa 1: performatividade do embate colonial ${ }^{11}$}

Eram duas horas da manhã do sábado quando eu e um colega pesquisador com quem acompanhávamos o levantamento de informações do Projeto Fronteiras da Secretaria de Direitos Humanos da Presidência da República, descemos de um dos vinte veículos militares que faziam parte de um espetacular operativo organizado por forças federais de defesa e segurança (2010); uma cidade muitas vezes descrita como índia e pacata. Estávamos em uma encruzilhada importante na vida noturna da cidade juntamente com duzentas pessoas fardadas e armadas (incluindo quatro mulheres, duas delas também fardadas) que corriam para ocupar os estabelecimentos e fechar as vias de saída de bares e ruas. O local-alvo era uma das duas ou três danceterias da cidade, frequentada por trabalhadores, pescadores, índios e recrutas; vale anotar que nessa cidade nem em 2010 nem em 2014 foram referidos ou detectados locais comerciais de prostituição. Depois de tomada a danceteria, um a um os homens foram revistados de forma truculenta. As mulheres aguardavam em pé a revista mais delicada de duas mulheres fardadas. A idade das muitas pessoas que estavam sem suas carteiras de identidade foi calculada por avaliação visual do oficial de alta patente que orgulhoso, fardado e com um facão no cinto comandava pessoalmente a operação, e de uma alta funcionária do poder judiciário evidentemente subordinada a ele. Algum oficial tirava fotos, enquanto outra funcionária do poder judicial filmava os rostos das pessoas que aguardavam para serem revistadas.

A operação tinha sido nos anunciada como "uma surpresa que vocês vão gostar". Depois com certo orgulho de tarefa bem feita, foi nos revelado que o objetivo da operação, baseada em "informações de inteligência”, era mesmo reprimir a exploração sexual de crianças e

\footnotetext{
${ }^{11}$ No seu livro Couro Imperial, Anne McClintock (2010) usa a ideia de embate imperial para nominar as tensões e agências em jogo nas relações do império britânico com as suas colônias, levando em conta a produção articulada do gênero, da raça e da classe. Na sua revisão da história do Alto Rio Negro, Gerardo Andrello (2006) usa a ideia de colonização para definir tal processo, no qual a ideia de "civilização" parece ter sido central na produção de diferenças e desigualdades e na afirmação das novas ordens de governamentalidade. $\mathrm{Na}$ sua concepção, compartilhada por outros estudiosos da história da Amazônia, "império" somente é usado com referência ao período imperial português e espanhol. É nesse sentido que uso a ideia de embate colonial e a referência a "civilização". As formas e os limites atuais desse "embate colonial" precisam ainda ser melhor estudados e compreendidos.
} 
adolescentes e o tráfico de drogas. Dezesseis pessoas que eram ou pareciam ser menores de idade (entre os aproximadamente quatrocentos frequentadores do bar) foram encaminhadas para o cartório e depois entregues aos seus pais. Nenhuma droga foi apreendida e nenhuma pista de "exploração" detectada. Contrário ao que ordena o Estatuto de Crianças e Adolescentes, o Conselho Tutelar foi intencionalmente mantido à margem da operação. $\mathrm{O}$ espetáculo, de fato, foi montado para nós, representantes de uma ONG de São Paulo que desenvolvia um projeto para a Secretaria de Direitos Humanos e estávamos aí com o Brasão da União terceirizado. Ninguém na cidade, funcionários públicos, militantes ou povoadores, falava em "tráfico de pessoas"; exceto nós. Brasília e São Paulo descendo em inspeção executiva sobre o último canto da Amazônia. Depois da desproporcionada performance pública e política, o local foi definitivamente fechado numa decisão judicial por permitir o ingresso de pessoas sem carteira de identidade. Nunca mais abriu; inclusive em 2014 o prédio tinha sido reformado e tinha outro uso comercial.

A cidade não tinha nenhum inquérito ou processo por tráfico de crianças e adolescentes nem por exploração sexual, apesar de ter muitos associados a abusos sexuais diversos, investigações por tal motivo contra todos os integrantes da Polícia Militar. De igual maneira, eram abundantes as narrativas de conselheiros/as tutelares, enfermeiras, funcionárias da assistência social, lideranças indígenas, e missionárias católicas sobre "abusos", "orgias" e "explorações" de garotas menores por parte de militares e, principalmente, de comerciantes locais poderosos.

Na mesma cidade conseguimos conhecer a história de Lulu, de treze anos, índia de nacionalidade estrangeira que morava com sua família subindo o rio. Sem muito mais dados, soubemos que ela foi morar com uma tia, também índia, perto da fronteira com o Brasil. A tia a entregou a um homem brasileiro, aparentemente indígena também, que a levou pelo rio até o distrito brasileiro fronteiriço. Conversando com ela em meio às dificuldades linguísticas, ela me disse que da comunidade fronteiriça pegaram um avião até a cidade onde nos encontrávamos. Quando tentaram sair da cidade com destino à capital foram detidos por um integrante da Força Nacional de Segurança que suspeitou da situação. Dizem que ela contou que tinha sido estuprada várias vezes e que não sabia nada mais. A menina estava num abrigo; o homem, preso na cidade, e o caso na justiça, esperando para ser 
resolvido. Uma dúvida restou para a equipe: se ela saiu de avião do distrito fronteiriço, só poderia tê-lo feito em um avião das forças militares brasileiras ou com a sua anuência. Como foi isso possível dadas as condições? No entanto, essa não foi uma questão para nenhum dos entrevistados que preferiam indicar "a cultura indígena" como principal fator que facilita tráficos, abusos e explorações.

Mais de dois anos depois, uma aparentemente cuidadosa operação investigativa deflagrada por instâncias de justiça e segurança federais capturou na cidade nove pessoas envolvidas com uma "rede de exploração sexual de meninas indígenas": três poderosos comerciantes locais/migrantes da mesma família, ao menos um oficial das forças militares e duas mulheres indígenas que agenciavam as moças, entre outras pessoas. A operação teve uma importante repercussão na mídia regional e nacional, e deu enorme visibilidade à dimensão étnica ${ }^{12}$. As investigações e julgamentos estão ainda em andamento, mas parece ter sido uma investigação rigorosa que ouviu mais de 14 meninas "exploradas", algumas das quais estão, segundo conselheiros tutelares, no sistema de proteção a testemunhas. Segundo diversas informações, uma moça de 11 anos, indígena, foi violentamente estuprada em um desses encontros. Nessa ação, uma investigação realizada por agentes federais, principalmente masculinos, deu materialidade jurídica às narrativas que desde 2010 ouvimos em campo por parte de agentes locais, civis, religiosas e, principalmente, femininas de governamentalidade. Foi somente na intensa reiteração por todos os canais possíveis (como o Projeto Fronteiras), na conexão com as políticas indigenistas federais, e na articulação pontual com um Procurador Federal que esse conjunto de agentes locais conseguiu transformar em "casos", em inquéritos, e em conhecimento jurídico o conhecimento que possuíam desde no mínimo três anos atrás. Por outro lado, mulheres locais, incluindo uma conselheira tutelar, nos contavam, a Adriana Piscitelli e a mim em 2014, que "isso sempre aconteceu", "desde que eu me conheço por gente", e que continua

\footnotetext{
${ }^{12}$ Essa parte da narrativa encontra referência no relatório da pesquisa "Trânsitos, crime e fronteiras: gênero, tráfico de pessoas e mercados do sexo no Brasil" (PISCITELLI et ali, 2015). Ali se encontra uma descrição completa da produção jornalística dessa operação e de algumas leituras locais da mesma, bem como sua compreensão ainda incompleta no marco mais geral de sociabilidades e sexualidades nessa cidade. Para aprofundar no conhecimento dessa cidade, sua história, relações sociais e região, ver Andrello (2006) e Lasmar (2005). Incluso no trabalho dessa última autora existem importantes pistas para a compreensão das relações exogâmicas e de violências associadas.
} 
acontecendo de formas diversas após a operação. O "isso", ao qual as mulheres se referiam não era a uma "exploração sexual" mais ou menos comercial, mas ao uso sexual dos corpos femininos jovens por parte de homens forasteiros ou investidos de poder local, e as retribuições ou ameaças em função do silêncio e do ocultamento ${ }^{13}$. Em uma notícia recente, o processo foi transferido da justiça federal e estadual para a justiça da Comarca; entrevistada por um jornal, a Juíza da Comarca afirmou desconhecer o caso e concluiu julgando que "Quem permite que essas meninas vão para a rua são os pais".

O combate à "exploração sexual de meninas indígenas" teve também lugar na Campanha da Fraternidade desenvolvida em 2014 nessa cidade. No início da Campanha a igreja local, com apoio de referentes regionais, ofereceu um curso de sensibilização sobre Tráfico Humano no qual participaram 120 leigos que, segundo foi mencionado, resultaram bastante motivados para se mobilizar publicamente contra aquilo que viam/sentiam/imaginavam como sendo "tráfico humano": o caso da exploração das meninas indígenas. Porém, foi o medo a represálias o que marcou os encaminhamentos práticos: "todos nós temos empregos públicos", nos disse um entrevistado que liderou parte do curso. Essa afirmação evidencia um medo coletivo à ação punitiva do próprio Estado/empregador em função da participação das pessoas nas ações públicas contra as violências e crimes que seriam associados (principalmente, a "exploração sexual”). O Estado, então, aparecia associado às práticas violentas de produção dos corpos, dos gêneros, das sexualidades e das posições de poder, bem como a ações extrajudiciais para restabelecer a ordem, os centros, as margens e as soberanias (DAS e POOLE, 2008). Porém, segundo o entrevistado, o grupo concordou em que era necessário "fazer algo". Na sexta feira após o carnaval fizeram uma passeata silenciosa, com a boca amordaçada e com uma vela acessa. Eram sete grupos, andaram durante uma hora e, segundo o entrevistado, a caminhada teve um alto impacto. Quando acabaram quase 300 pessoas teriam se incorporado na passeata.

No meio de Estados multiformes, ambivalentes e carnalmente enredados, de tráficos e fronteiras, de comerciantes, militares e explorações, está o Lepo Lepo. Comerciantes e militares ocupam,

\footnotetext{
${ }^{13}$ Ideias como essa surgiram das conversas em e depois do campo. Agradeço a Adriana pelos intercâmbios e a experiência do campo.
} 
como já vimos, um lugar destacado nas acusações sobre explorações e abusos sexuais; porém o lugar é marcadamente diferente. Os primeiros tendem a ser uma instituição do poder local altamente territorializada e envolvida em diversas histórias de violências, abusos ou crimes; em geral com famílias constituídas e com trajetórias conhecidas. Os segundos, "os militares" (e como veremos os "aeronáuticos"), são sujeitos voláteis, muitos deles jovens com corpos sarados, empregados do Estado, desterritorializados ou arraigados "fora", cuja alta rotatividade os transforma não apenas em uma ameaça sempre permanente de abandono, mas em um bem de consumo sexual e conjugal sempre disponível. Uma jovem de etnia Tukana afirmava em 2014, conversando com Adriana Piscitelli e comigo, que há muito mais homem que mulher na cidade, por causa dos militares; que há da aeronáutica, da marinha e também do exército e que as meninas gostam muito deles, algumas casaram e foram embora com eles para outros lugares. Outras ficaram grávidas e eles não assumem. "Eles ficam aqui 2 anos, então se quiser casar tem que ir rápido." 14

Essas formas de desejo se materializaram durante o trabalho de campo nas cenas de interação e sociabilidade de um grupo de homens da aeronáutica que, segundo soubemos, estariam na cidade um curto tempo realizando práticas de horas de voo. Eram homens que se destacavam pelas suas corporalidades e estéticas. Eles, onipresentes durante essa semana nos espaços de festa e paquera, pareciam ser a "carne nova" na cidade, várias mulheres de diversas idades e tipos físicos circulavam ao redor deles. Elas ficavam perto, arrumadas, relativamente disponíveis e coquetes; eles as buscavam para dançar e elas aceitavam, mas logo depois elas procuravam ora as suas amigas, de volta, ora os seus pares masculinos (por condição social, corporalidade e geração) para dançar forró. Eles, que também priorizavam a homo e endossociabilidade, circulavam, buscavam entre as várias que os acompanhavam, mas não parecia acontecer com nenhuma. Não parecia que por eles serem a carne branca mais nova e desejada no pedaço elas fossem de fácil e direto acesso. Em nenhum momento vimos (como sim em Tabatinga ou em Altamira) mulheres realizando danças explicitamente erotizadas ou sugestivas para eles, subidas em palcos ou fazendo strip. Inclusive, essa imagem se fez mais

${ }^{14}$ Lasmar (2005 p. 154) sugere que esse interesse pode ser mapeado por bairros (isto é, "classe", posição socioeconómica e configurações étnicas), sendo que no seu estudo as meninas de bairros como Praia buscariam decididamente não namorar ou casar com homens indígenas. 
forte quando, em contraste, em uma noite de festa na casa de shows mais badalada da cidade dois dos aeronáuticos mais jovens, altos, brancos e de corpos muito trabalhados, subiram no palco para se exibir dançando o Lepo Lepo com direito a levantada da camiseta para expor seus abdomens malhados ${ }^{15}$. A mulherada gritou enlouquecida; porém, no percurso da noite nenhum deles dois conseguiu ficar com as moças com quem tentaram. Por fim, os moços convidaram a mulherada a se fazer presente numa festa no final de semana seguinte chamada AeroNight. É claro, nada sabemos sobre arranjos privados.

\section{Narrativa 2: Performatividades de governamentalidade no cosmopolitismo amazônico}

Em Tabatinga, cidade também amazônica e também fronteiriça, mas bem mais movimentada e "cosmopolita" que São Gabriel da Cachoeira, existe, entre os mais de quatro locais de sexo comercial, uma casa de prostituição artesanal identificada pelas pessoas que nela trabalham e pelas pessoas da cidade, como estrangeira. Isto é, as pessoas, as músicas e a linguagem são identificadas como pertencentes a um dos países vizinhos. Algumas semanas após ser aberta, em 2010, recebeu uma visita da Polícia Civil. A indagação policial teve dois focos principais que resultam muito úteis para a nossa discussão: primeiro, que não houvesse menores de 18 anos trabalhando no local, segundo, que tampouco houvesse brasileiras trabalhando aí. Se o enfrentamento à "exploração sexual de crianças e adolescentes" ressalta na preocupação policial, ressalta também a ausência de qualquer menção a "manutenção de casa de prostituição" e, muito visivelmente, a "tráfico de pessoas". Pelo contrário, o recomendado pela polícia foi ter estrangeiras trabalhando ali, como se o pequeno prostíbulo fosse uma extensão do território nacional do país vizinho.

Quatro anos depois, em dezembro de 2014, essa casa de prostituição recebe mais uma visita policial. Dessa vez, uma "operação". Segundo a matéria de imprensa que divulgou o evento "...colombianas são

\footnotetext{
${ }^{15}$ O Lepo Lepo é uma dessas tantas músicas populares brasileiras que abordam de maneiras diversas as "economias sexuais". No refrão eles tentavam imitar a coreografia das dançarinas: https://www.youtube.com/watch?v=AHVS5DW434g
} 
resgatadas de boate durante operação policial." 16 Ainda segundo essa matéria, o "tráfico de pessoas" seria investigado pois as "jovens" se prostituiriam de maneira obrigada. No corpo da noticia ainda se menciona que as mulheres teriam sido "resgatadas" e que a "boate" teria sido fechada. Diz a reportagem jornalística que dita ação fez parte da operação "Brasil Integrado" realizada em 10 munícipios do estado de Amazonas por parte de forças tarefa coordenadas pela Secretaria de Segurança Pública desse estado. A administradora da casa me narrou o evento um pouco angustiada, afirmando que teve Polícia Federal no operativo e que houve bastante pressão sobre a "irregularidade" da presença dela e das mulheres no "Brasil"; inclusive narrou que a polícia tinha indagado sobre os arranjos econômicos na administração do negócio. Contudo, em momento algum a administradora do local lembra de ameaças ou advertências dos agentes de segurança referentes a tráfico de pessoas que levasse a "resgate" algum; inclusive, segundo ela, a "boate" não foi fechada.

Essas duas cenas, vistas em conjunto, e relevando temporariamente informações que ainda desconheço (como, por exemplo, a maneira como "tráfico" e "resgate" chegou na matéria jornalística), nos permitem apreender empiricamente o processo de produção governamental de fronteiras em Tabatinga a partir da capilarização e da reelaboração local de certas políticas públicas (nesse caso, tráfico de pessoas e exploração sexual). Entre 2010 e 2014 mudamos de uma vistoria da Polícia Civil para um operativo conjunto de forças tarefa, incluindo Polícia Federal em termos de segurança e integração nas fronteiras e de controles migratórios e de condições do trabalho, evento inédito para essa casa e para muitos outros negócios de "estrangeiros" nessa cidade. Nesses anos mudamos do foco na "exploração sexual de crianças e adolescentes" e da presença de brasileiras para o "resgate de [estrangeiras]" sobre cuja idade a matéria não diz nada. Em geral, é possível afirmar que entre 2010 e dezembro de 2013 as autoridades públicas de Tabatinga não mencionavam o "tráfico de pessoas" nem como uma problemática social nem como um interesse político. Diferentemente da "prostituição de meninas" e de outros assuntos associados às sexualidades adolescentes, indígenas, locais. A chave explicativa local para essa janela é, como vimos na

16“No AM, colombianas são resgatadas de boate durante operação policial". G1 AMZONAS. 6 de dezembro de 2014. Acessado em 15 de junho de 2015 em http://g1.globo.com/am/amazonas/noticia/2014/12/no-am-colombianas-saoresgatadas-de-boate-durante-operacao-policial.html 
anterior sessão, a Campanha da Fraternidade 2014 da Igreja Católica e sua articulação contingente com a expansão e multidimensionalidade das políticas federais antitráfico e seu encontro com as políticas de segurança, defesa e integração das fronteiras (e da Amazônia). Nesse sentido, vale a pena atentar rapidamente à maneira como está acontecendo a capilarização dos discursos antitráfico nessa cidade. Essa informação nos permitirá compreender um outro desdobramento de governamentalidade na produção destas fronteiras.

Segundo o material divulgado localmente, como vimos na sessão anterior, a Amazônia e as cidades fronteiriças são apresentadas como territórios vulneráveis, bem como a migração e a permanência não apenas ilegal mas "precária" no país, são definidos a priori como vetores que facilitam a existência do tráfico. No desdobramento dessas ideias promovidas pela Igreja Católica, a partir do final de 2013, e durante 2014 e 2015, ativistas laicos e religiosos vinculados a essa igreja junto com agentes locais dos direitos humanos e da assistência social, entre outros, principalmente mulheres, realizaram nessa cidade e em cidades vizinhas diversas ações públicas de "sensibilização" para a prevenção ao tráfico de pessoas. Essas atividades têm estado marcadas por uma linguagem fortemente religiosa e civilizatória incluso com a participação de agentes federais de segurança e justiça, representantes da mídia, funcionários públicos de diversos âmbitos, pesquisadores, lideranças indígenas, etc. Se bem a Campanha da Fraternidade usa uma definição de tráfico de pessoas baseada em acordos internacionais, os usos e as reelaborações locais seguem as sendas das opiniões, interesses e emoções morais dos agentes (a maioria mulheres não indígenas, algumas brancas do sul do país ou europeias, e algumas indígenas; também homens funcionários federais) e sem nenhuma preocupação com a delimitação de categorias, de âmbitos administrativos, ou com a reprodução de estruturas de poder e de desigualdades muitas vezes de franco viés nacionalista e colonial. Isto é, por exemplo, em uma atividade de sensibilização com população indígena, uma agente de saúde branca do sul do país usava a terminologia do "tráfico de pessoas" para criticar a circulação de crianças indígenas para além dos seus imaginados núcleos familiares ou a participação de homens peruanos na vida sexual e econômica local, ou, inclusive, deslizando para "violência contra as mulheres" e criticando as mulheres indígenas que não compram máquina de lavar com o dinheiro da Bolsa Família. Nessa lógica, "as culturas locais" têm ocupado um lugar privilegiado em explicações recorrentes de 
muitos dos agentes: promiscuidade, "adoção brasileira", início precoce de relações sexuais, entre outras ideias.

Nesse processo de "capacitação" e "sensibilização" tem se destacado o lugar dado a "os peruanos" e a "o Peru" como materialização privilegiada da ameaça; isto é, em diversas piadas e comentários soltos, mas também em "denúncias" informais por parte de ativistas locais "os peruanos" ou "o Peru" foram mobilizados como agentes do tráfico ou como símbolo da ameaça. Isso se corresponde com uma consistente lógica local de produção de desigualdades, compartilhada por colombianos e brasileiros, que coloca a tudo que tem a ver com o Peru no local mais baixo da organização social. Inclusive, a ilha peruana de Santa Rosa foi-me indicada em dezembro de 2014 por uma religiosa da Campanha como o lugar ideal para "ver" tudo acontecer; diversas narrativas se teceram sobre essa ilha como um lugar no qual "meninas" colombianas e brasileiras seriam exploradas e violentadas em festas nos finais de semana. Por tal motivo, tem existido uma pressão dessas ativistas sobre a Marinha do Brasil e sobre a Polícia colombiana para vigiar, controlar e reprimir a mobilidade noturna através do rio, principalmente de mulheres jovens ${ }^{17}$. Nesse sentido, boa parte das angustias de agentes do Estado e ativistas tem estado voltadas sobre "prostituição de meninas" e, a partir daí, sobre espaços de lazer, relações e mobilidades intra e transfronteiriças de adolescentes associadas com sexualidade (e dinheiro). Inclusive os operativos policiais de diversa escala para "apreender" adolescentes em "situações de risco", e discursivamente associados com tráfico de drogas, estão sendo muito mais frequentes e maiores em Tabatinga, chegando a recentes "apreensões" de mais de 100 garotos numa noite, com o aval do Conselho Tutelar, para serem "entregues" aos pais (é preciso mencionar que entre 2011 e 2013 aconteceram algumas operações de repressão à presença de menores de 18 anos na rua depois de determinados horários noturnos; porém, não tenho registro de formas, tamanhos e proporções semelhantes a estas últimas).

Resulta interessante notar como esse conjunto de demandas e de caracterizações que "o tráfico" vem assumindo (alteridade como

\footnotetext{
${ }^{17}$ Albuquerque e Paiva, no seu artigo nesse dossiê descrevem desde vários pontos de vista a facilidade da mobilidade e a excepcionalidade de controles de fronteiras mais fortes nessa tríplice fronteira. Ao parecer, essa construção de pânico que associa Peru/peruanos, jovens e mulheres, estaria estimulando práticas de controle policial/militar da fronteira.
} 
ameaça, prostituição de meninas e culturas locais problemáticas), se corresponde de maneira muito forte com as leituras que agentes de governamentalidade e humanitarismo vinculados a discursos religiosos católicos, principalmente mulheres não índias e não locais, promoviam até 2013 ao redor da "exploração sexual" (OLIVAR, 2013). Esses agentes promoviam uma "visão de fora", de "direitos humanos", bastante moral, emotiva e crítica à "cultura local", que contrastava significativamente com as perspectivas de agentes locais do Conselho Tutelar ou da Assistência Social, bem como com os posicionamentos de policiais civis responsáveis pela investigação desses crimes. Nas conversas com conselheiros/as tutelares e com funcionárias da assistência social até dezembro de 2013, e incluso com policiais civis, "tráfico de pessoas" não aparecia e "exploração sexual de crianças e adolescentes" era uma questão sempre presente, mas não constituía uma prioridade. E não constituía prioridade porque não era uma demanda social (diferentemente de abuso sexual, violências intrafamiliares, registros, ausências escolares, tráfico de drogas) nem uma demanda política forte dos governos federais ou estaduais, então esses agentes locais dos Conselhos Tutelares ou dos centros de referência em assistência social, tipicamente pessoas locais de baixa formação - ou esposas de militares -, com baixos salários, contratos precários e pouca capacitação; priorizavam o que parecia como mais urgente no nível local. Esses agentes conheciam de perto as moças e os moços ("gays") adolescentes que seriam "explorados", já trabalharam com elas, já tentaram "tirar" dessas vidas e já conheciam, como habitantes locais e como escutas desses garotos, diversas histórias, personagens e detalhes dessas relações. No caso da Polícia Civil existe a dificuldade enorme de "provar" a exploração.

Tudo isso implicou uma dupla tensão entre agentes do Estado nos diversos âmbitos e níveis e também entre agentes de governamentalidade como ativistas religiosas. De um lado, entre conselheiros tutelares e "os militares" ou policiais federais e estaduais, pois conselheiros tutelares e assistentes sociais - e juízes de infância sabem que são esses agentes federais os principais "clientes" ou parceiros amorosos, sexuais e comerciais - e eventuais exploradores ou abusadores - dos e das garotas. Funcionários masculinos, armados, estaduais ou federais com salários significativamente superiores e ótimas condições empregatícias. De outro lado, agentes civis federais (justiça, por exemplo) e agentes religiosas ou civis de governamentalidade como freiras, missionárias, professoras 
universitárias ou representantes de ONGs, que estão encampando os discursos antitráfico como uma oportunidade de "mudar mentalidades", consideram que esses agentes locais, profundamente locais, "não fazem nada", mesmo "sabendo tudo que acontece".

Apesar das generalizações sobre "fronteira" e sobre "Amazônia", vemos então diferenças significativas entre as duas cidades, em praticamente todos os planos observados. Nesse artigo resulta impossível aprofundar esse aspecto, mas vale a pena mencionar algumas no sentido das formas de governo e da capilarização do tráfico/exploração e algumas conexões possíveis com as formas como a sexualidade, a economia e o gênero se organizam localmente.

Em São Gabriel, como vimos, a presença das forças militares, particularmente do exército, é massiva e contundente, marcada por uma enorme assimetria geral de recursos, capitais e poderes com relação às formas civis e locais de governo, e a partir dessa posição intervêm de maneira autárquica em âmbitos da vida social e política da cidade, como o enfrentamento à exploração sexual, que somente lhe corresponderiam em estados de exceção. Igualmente, a experiência erótica que implicam os corpos dos "aeronáuticos", por exemplo, não tem comparação ou concorrência com Tabatinga, pois não há na primeira outra categoria análoga - de homens forasteiros, situacionalmente solteiros, com boa e estável capacidade financeira e corporalidades supervalorizadas - que faça presença massiva na cidade/região. A configuração em Tabatinga é completamente diferente, apesar de que também nela o lugar do governo militar é fundamental. Primeiro, porque o exército tem muito menos poder material que na outra cidade (trata-se de um Batalhão e não de uma Brigada, como em São Gabriel); mas também, relacionalmente, porque se trata de uma cidade muito maior em termos de população, importante na configuração regional do médio amazonas transnacional, com presença crescente de diversos poderes civis dos níveis locais, estaduais e federais do Estado, incluindo universidades públicas, com uma diversificação econômica maior, com intensos fluxos transfronteiriços e com importantes conexões transnacionais que a transformam em um espaço de cosmopolitismo amazônico. 
Essas diferenças entre São Gabriel e Tabatinga são relevantes, pois, se na segunda narrativa a Igreja ganhou um protagonismo público e político altamente efetivo na Campanha da Fraternidade, e pelo caminho do Tráfico conseguiu mobilizar massivamente discursos civilizatórios sobre sexualidades locais com a parceria do Estado, no primeiro caso a Igreja foi o claro opositor (ou mediador?) à violência dos poderes coloniais militares e comerciais sobre as "meninas indígenas", tendo inclusive uma freira estrangeira ameaçada de morte. A Igreja em São Gabriel, fortalecida incluso pelas organizações indígenas, atualizou seu lugar da mediação social e de resistência "popular" em oposição aos poderes do "Estado".

\section{Algumas considerações finais}

Nesse artigo busquei apresentar as maneiras como "o Estado" se produz nessas fronteiras amazônicas tomando como recorte empírico o caso da articulação entre políticas de fronteiras e políticas de tráfico, bem como a capilarização prática dessa articulação em duas cidades fronteiriças amazônicas.

Para esse exercício resultaram inspirações fundamentais as abordagens que compreendem o Estado desde sua operação multidimensional, policentrada, desde suas margens territoriais e conceituais, e desde a cotidianidade de agentes e de readequações de limites legais (SHARMA e GUPTA, 2006; DAS e POOLE, 2008). Essa abordagem fez necessária a inclusão da noção foucaultiana de governamentalidade (FOUCAULT, 2008; LEMKE, 2000), para chamar a atenção sobre "extensões", desdobramentos e capilaridades das formas maior ou menormente institucionalizadas de poder. Do mesmo modo, a noção de "atos performativos" desenvolvida por Butler (1990) me resultou útil para entender como a capilaridade apresentada nos documentos e nas narrativas de campo, não é mera aplicação ou reprodução local mais ou menos falida ou mais ou menos exitosa de estruturas ou de dispositivos de governo previstos nos âmbitos superiores ou centralizados do Estado, mas elaborações locais que de maneiras diversas negociam, criam e produzem relações e materialidades (eis o performativo), entre valores morais e sociais, deveres laborais e éticos (de Estado), interesses e desejos particulares e possibilidades contingentes de ação. Assim, a "capilaridade" não parece uma 
particularidade das margens, nem das pontas, mas se desenha como condição material e relacional de possibilidade para a operação do Estado, em redes que conectam o local, o transfronteiriço, o nacional e o transnacional.

Por outro lado, retomei as ideias de Grimson (2003) e de Albuquerque (2010; 2015) sobre a fronteira como um processo permanente de construção, as elaborações de Zárate (2008) para colocar o território e o processo polifônico de produção de fronteira como centro, como ponto de vista, e as análises da fronteira como "mito-conceito" propostas por Serje (2005).

Inicialmente apresentei o processo e os caminhos de articulação entre "tráfico" e "fronteiras" em políticas e discursos de âmbito federal, a partir de alguns objetos políticos que serviram de marcadores. Nos documentos das políticas antitráfico, a fronteira se desdobrou de ser referência metafórica dos deslocamentos internacionais, a ser um território literalizado e definido como ameaça per se. Isto é, a partir destas gestões e agências políticas a fronteira não importa apenas enquanto símbolo dos processos migratórios (o oceano que se atravessa de avião, os controles de aeroporto), mas, enquanto território com mapas, extensões, populações, caraterísticas próprias, vizinhos, mobilidades internas; territórios que precisam ser vigiados, controlados e estudados. Ainda mais, quando essas fronteiras são Amazônicas, as duas imaginações territoriais fronteira e Amazônia se articulam de maneira bastante fácil para construir um cenário de múltiplas e indiscutíveis ameaças que cruzam as "culturas locais" (ora amazônicas, ora indígenas), a história colonial, os projetos de desenvolvimento, as dinâmicas migratórias, as relações de gênero, a pobreza, as relações interétnicas, entre outras que em nenhum dos documentos aparecem suficientemente explicadas e muito menos nuançadas ou problematizadas.

Já do lado das políticas de fronteiras, o "tráfico de pessoas" somente começou a ser uma preocupação destas políticas a partir do ano de 2011. Nessa construção, o tráfico de pessoas aparece como mais um dos "crimes transfronteiriços"; isto é, devido à lógica e à arquitetura institucional que organiza as políticas brasileiras contemporâneas de fronteiras, baseada em segurança, defesa e integração, o "tráfico de pessoas" tem reforçada a sua dimensão de justiça criminal, antes que a sua dimensão de promoção de direitos humanos. Ou, melhor dizendo, 
a segurança, a integração e a defesa se constituem nessa lógica como condições para a promoção dos direitos humanos.

Se bem a gestão de articular claramente territórios de fronteira e tráfico de pessoas pode se mapear documentalmente desde 2010-2011, é somente a partir de 2014 que essa conjunção começou a se fazer presente em alguns territórios, como Tabatinga, pelo impulso da Igreja Católica sobre uma arquitetura institucional e discursiva de combate ao tráfico de pessoas gestada transnacional e federalmente por mais de uma década. O governo federal brasileiro, em particular os órgãos de direitos humanos, de segurança e de justiça, aparecem como o principal agente mobilizador dessa articulação. Porém, esse protagonismo está atrelado materialmente a outros agentes nacionais ou transnacionais de governamentalidade ou, em diversos casos, é por estes puxados e pressionados à ação: organizações civis nacionais e estrangeiras, organismos multilaterais, militantes individuais, universidades e, como já dissemos, organizações religiosas. As únicas organizações locais ou regionais que ressaltam nesse panorama documental são a ONG Sodireitos, de Belém, que atua em articulação com importantes organizações transnacionais, e a Universidade Federal de Amazonas.

Na segunda parte, apresentei duas narrativas provenientes de São Gabriel da Cachoeira, tríplice fronteira com a Venezuela e a Colômbia, e de Tabatinga, fronteira com o Peru e a Colômbia, num recorte temporal que atravessou uma janela importante nessa análise da produção recente de fronteiras: 2010-2014. Nessas narrativas mostrei como o Estado, primeiro, está longe de ser uma força periférica ou escassa no governo e na produção cotidiana da cidade, da imaginação fronteiriça, da economia local e dos corpos. Esses Estados aparecerem como arquiteturas amplas, complexas, fortes, conectadas com estruturas de poder transnacionais e locais, e atomizadas em pessoas, organizações e relações que marcam a forma da sua governamentalidade e a vida social e econômica - sexual e reprodutiva - local. Segundo, esses estados e estas formas de governamentalidade estão em claro processo de transformação e ampliação, incluindo a abertura de espaços para agentes civis, locais e femininos. Terceiro, o processo de fronteirizaçao é tensionado e complementado por formas e agentes de governamentalidade cujo papel no processo histórico de fronteirização foi e, pelo visto, continua sendo central. Refiro-me aos discursos e às organizações religiosas, particularmente à Igreja 
Católica e sua estrutura missionária que muda entre as diversas cidades. Quarto, mostrei como, apesar das transformações e multiplicidades, essa presença está marcada por uma forte mas variável assimetria que privilegia a produção e o governo militar masculino da fronteira e que pode implicar confrontos diretos com os pequenos ou emergentes poderes locais, civis e muitas vezes femininos. A assimetria está definida pela desigualdade abismal - com relação a âmbitos civis e níveis locais/estaduais do Estado- em termos de recursos humanos, logísticos e financeiros, pelo lugar simbólico, econômico, erótico e político que ocupam as forças militares e seus integrantes (mas também outros importantes poderes masculinos como o narcotráfico), e pelo poder concedido pela Federação durante muitas décadas para governar a região amazônica. Por último, essas arquiteturas de governamentalidade, suas transformações e assimetrias têm uma importante variação, como se faz evidente entre São Gabriel e Tabatinga, que deve ser ressaltada no intuito de quebrar generalizações sobre "a Amazônia" e "a fronteira". A Amazônia e as fronteiras são unidades imaginativas que na empiria demonstram ser extremamente diversas em todas as dimensões de análise social e política, inviabilizando assim seu uso como categorias explicativas automáticas.

$\mathrm{Na}$ análise do "processo de fronteirização" e da produção do "mitoconceito" de fronteira, ganharam um lugar muito especial os discursos de "mudar" as culturas locais indígenas e as culturas locais colonizadoras, o dever de suspeitar dos estrangeiros e dos desejos de mobilidade territorial e econômica, a necessidade de "resgatar" colombianas e de "apreender" adolescentes em risco, bem como a tensa relação local com as formas institucionalizadas de poder (Estado, pastores, comerciantes, narcotraficantes) que cruza pelo desejo erótico, o desejo governamental, a experiência da violência e a desconfiança moral. Assim, na capilarização das políticas antitráfico articuladas com políticas de fronteiras, muito além de combater um "tráfico de pessoas" sobre o qual ninguém parece ter dados concisos, é "a fronteira" e "a Amazônia" as que parecem fervilhar em uma gestação mítica (SERJE, 2005) bastante particular na qual as fronteiras internacionais amazônicas são assim construídas como sexualmente perigosas, especialmente para mulheres jovens e indígenas que, portanto, deverão ser protegidas de estrangeiros, de colonizadores, do próprio Estado e de suas próprias culturas. 
Como afirmam Das e Poole (2008), retomando as propostas de Agamben sobre o homo sacer, nessas margens nas quais a excepcionalidade de um Estado liberal imaginado não é temporal, a soberania, antes que sobre os territórios, é sobre os corpos. Isto é, as políticas e discursos de combate ao tráfico de pessoas/exploração sexual deram à fronteira e a suas políticas contemporâneas a oportunidade de atualizar na lógica dos crimes e dos direitos humanos, do Estado liberal federativo e em busca da integração nacional, uma velha carnalidade e um velho âmbito de ação colonial: o corpo e a sexualidade. Ao colocar no escopo da segurança, da defesa e da integração determinadas sexualidades e corporalidades, determinadas formas de construção do parentesco, em conexão com mobilidades territoriais e com formas social e historicamente aceitas de acessar o dinheiro, a articulação entre políticas contemporâneas de fronteiras e políticas antitráfico/exploração, atualizam o histórico procedimento colonial de penetrar as formas locais de moralidade, de sexualidade e de intimidade, para concebê-las assim como objetos de atraso, de violência, de crime e de iniquidade social sobre as quais deve recair um desejo permanente de segurança, de controle e de mudança.

\section{Referências}

AGUSTÍN, L. Sex at the margins: migration, labor markets and the rescue industry. London/New York: Zed Books, 2007.

ALBUQUERQUE, J. L. C. Procesos de fronterización y sentidos de pertenencia entre Brasil y Paraguay. In: HERNÀNDEZ, A. H.; CAMPOS-DELGADO, A. (Coord.). Líneas, limites y colindancias: mirada a las fronteras desde América Latina. Tijuana/Ciudad del México: Colegio de la Frontera Norte/CIESAS, 2015.

A dinâmica das fronteiras: os brasiguaios na

fronteira entre o Brasil e o Paraguai. São Paulo: Annablume, 2010.

ANDRELlO, G. Cidade do Índio. São Paulo: UNESP/ISA; Rio de Janeiro: NUTi, 2006. 
APONTE MOTTA, J. Leticia y Tabatinga: transformación de un espacio urbano en la Amazonia. Tesis de Maestría en Estudios Amazónicos. Leticia: Universidad Nacional de Colombia, 2011.

ASBRAD. Disseminação da metodologia de atendimento às vítimas do tráfico de pessoas nas fronteiras. Guarulhos: ASBRAD/SEDH, 2012.

BLANCHETTE, T.; SILVA, A. P. On bullshit and the trafficking of women: moral entrepreneurs and the invention of trafficking of persons in Brazil. Dialectical Anthropology. v. 36, n. 1-2, p. 107-125, junho 2012

BRASIL. Ministério da Integração Nacional. Bases para uma proposta de desenvolvimento e integração da Faixa de Fronteira. Brasília: Grupo de trabalho interfederativo de integração fronteiriça, 2010.

BRASIL. Secretaria Nacional de Justiça. Pesquisa sobre tráfico de pessoas nas áreas de fronteira. Brasília: Ministério da Justiça, 2013a.

BRASIL. Secretaria Nacional de Justiça. II Plano nacional de enfrentamento ao tráfico de pessoas. Brasília: Ministério da Justiça, $2013 b$.

BUTLER, J. Performative acts and gender constitution: an essay in phenomenology and feminist theory. In: CASE, Sue-Ellen. (ed.) Performing feminisms: feminist critical theory and theory. New York: John Hopkins University Press, 1990. p. 270-282.

DAS, V.; POOLE, D. El estado y sus márgenes: etnografias comparadas. Revista Académica de Relaciones Internacionales, n. 8, jul. 2008.

DIOCESE DO ALTO SOLIMÕES. Campanha da Fraternidade 2014: Tráfico Humano. Tabatinga: [s.n.] 2013.

FOUCAULT, M. Nascimento da Biopolítica. São Paulo: Martins Fontes, 2008. 
GRIMSON, A. Los procesos de fronterización: flujos, redes e historicidad. In: GARCÍA, Clara Inés (ed). Fronteras: territorias y metáforas. Medellín: Hombre Nuevo Editores, 2003. p. 15-34.

GRUPO DAVIDA. Prostitutas, 'traficadas' e pânicos morais: uma análise da produção de fatos em pesquisas sobre o 'tráfico de seres humanos. Cadernos PAGU, Campinas, n. 25, 2005. p. 153-185.

HIRATA, D. Segurança pública e fronteiras: apontamentos a partir do "Arco Norte". Cienc. Cult., São Paulo, v. 67, n. 2, jun. 2015.

ICMPD/UNODC/SNJ. Termos de Referência para a Pesquisa Nacional sobre Tráfico de Pessoas nas Áreas de Fronteiras. Brasília: [s.n.] 2012.

KEMPADOO, K. The war on human trafficking in the Caribbean. Race and Class, v. 49, n. 2, p. 79-84, 2007.

Mudando o debate sobre o tráfico de mulheres. Cad. Pagu, Campinas, n. 25, p. 55-78, dec. 2005.

LASMAR, C. De volta ao lago de leite: gênero e transformação no Alto Rio Negro. São Paulo: UNESP/ISA; Rio de Janeiro: NUTi, 2005.

LEAL, M. (org). Pesquisa sobre tráfico de mulheres, crianças e adolescentes para fins de exploração sexual comercial no Brasil: relatório nacional. Brasília: CECRIA, 2002.

LEMKE, T. Foucault, governmentality, and critique. Rethinking marxism, v. 14, n. 3, p. 49-64, 2002.

LOWENKRON, L. Gênero, Fronteiras e Estado: a construção do tráfico de pessoas em investigações e inquéritos policiais. Relatório de pesquisa de pós-doutorado apresentado à Fundação de Amparo à Pesquisa do Estado de São Paulo (FAPESP), 2014.

McCLINTOCK, A. Couro Imperial: gênero, classe e raça no embate imperial. Campinas: Editora da Unicamp, 2010.

O CONNELL, D. J. Absolving the state: the trafficking slavery metaphor. Global Dialogue. Volume 14, number 2, summer/autumm 2012. 
OLIVAR, J. M. Mercados do sexo em territórios transfronteiriços: gênero e circulações na fronteira Brasil-Colômbia. Relatório final de pesquisa. FAPESP, process 2010/50077-1. Núcleo de Estudos de Gênero -PAGU / Unicamp. Campinas: PAGU/FAPESP, 2012.

OLIVEIRA, M. Las paradojas de la trata y el tráfico de mujeres de la amazonía brasileña en España. Dissertação de mestrado Máster Oficial en Género, Identidad y Ciudadanía. Universidad de Huelva, 2011.

PISCITELLI, A. et al. Trânsitos, crime e fronteiras: gênero, tráfico de pessoas e mercados do sexo no Brasil. CNPq Processo 404868/2012-6. Campinas: Núcleo de Estudos de Gênero PAU/UNICAMP, 2015.

PISCITELLI, A. Trânsitos: brasileiras nos mercados transnacionais do sexo. Rio de Janeiro: CLAM/Eduerj, 2013.

- Procurando vítimas do tráfico de pessoas: brasileiras na indústria do sexo na Espanha. Revista interdisciplinar da mobilidade humana. v. 19, n. 37, p. 11-26, 2011.

. Entre as 'máfias' e a 'ajuda': a construção de conhecimento sobre tráfico de pessoas. Cadernos PAGU, Campinas, n. 31, p. 29-64, julho-dezembro 2008.

Apresentação: gênero no mercado do sexo. Cadernos Pagu, Campinas, n. 25, p. 7-23, 2005.

SERJE, M. El revés de la nación: territories salvajes, fronteras y tierras de nadie. Bogotá: Universidad de los Andes, 2005.

SHARMA, A.; GUPTA, A. Introduction. In: (org.). The Anthropology of the State, a Reader. Oxford, Blackwell Publishing, 2006. p. 1-43.

SCHILLER, N. G.; SALAZAR, N. Regimes of Mobility Across the Globe. Journal of Ethnic and Migration Studies, Vol. 39, No. 2, p. 183-200, 2012.

SODIREITOS-GAATW/REDLAC. Pesquisa tri-nacional sobre tráfico de mulheres do Brasil e da República Dominicana para o 
Suriname: uma intervenção em rede. Belém: Sodireitos, 2008.

SPRANDEL, M. Anita. Vou pra rua e bebo a tempestade: observações sobre os dissabores do guarda-chuva do tráfico de pessoas no Brasil. Palestra oferecida no Seminário Internacional Re-Pensando Gênero e Feminismos: 20 anos do Núcleo de Estudos de Gênero PAGU. Campinas: PAGU/Unicamp, 2014.

TEIXEIRA, F. L'Italia dei Divieti: entre o sonho de ser européia e o babado da prostituição. Cadernos Pagu, v. 31, p. 275-308, 2008.

TORRES, I.; OLIVEIRA, M. Tráfico de mulheres na Amazônia. Florianópolis: Editora Mulheres, 2012.

ZÁRATE BOTÍA, C. Silvícolas, siringueros y agentes estatales: el surgimiento de una sociedad transfronteriza en la amazonia de Brasil, Perú y Colombia 1880-1932. Leticia: Universidad Nacional de Colombia, 2008. 